\title{
Intracranial aneurysms: review of current treatment options and outcomes
}

\section{Brad Seibert ${ }^{1}$, Ramachandra P. Tummala ${ }^{2,3}$, Ricky Chow $^{3,4}$, Alireza Faridar ${ }^{3}$, Seyed A. Mousavi ${ }^{5}$ and Afshin A. Divani ${ }^{2,3}$ *}

\author{
${ }^{1}$ Department of Biomedical Engineering, College of Science and Engineering, University of Minnesota, Minneapolis, MN, USA \\ 2 Department of Neurosurgery, University of Minnesota, Minneapolis, MN, USA \\ ${ }^{3}$ Department of Neurology, University of Minnesota, Minneapolis, MN, USA \\ ${ }^{4}$ Department of Mechanical Engineering, College of Science and Engineering, University of Minnesota, Minneapolis, MN, USA \\ ${ }^{5}$ Department of Neurology, Isfahan University of Medical Sciences, Isfahan, Iran
}

\section{Edited by:}

Shakir Husain Hakim, Max Institute of Neurosciences, India

\section{Reviewed by:}

Marc Lazzaro, Medical College of Wisconsin, USA

Michihiro Tanaka, University Hospital

Zurich, Switzerland

*Correspondence:

Afshin A. Divani, Department of Neurology, University of Minnesota, 420 Delaware Street Southeast, MMC 295, Minneapolis, MN 55455, USA.

e-mail:divani@umn.edu
Intracranial aneurysms are present in roughly $5 \%$ of the population, yet most are often asymptomatic and never detected. Development of an aneurysm typically occurs during adulthood, while formation and growth are associated with risk factors such as age, hypertension, pre-existing familial conditions, and smoking. Subarachnoid hemorrhage, the most common presentation due to aneurysm rupture, represents a serious medical condition often leading to severe neurological deficit or death. Recent technological advances in imaging modalities, along with increased understanding of natural history and prevalence of aneurysms, have increased detection of asymptomatic unruptured intracranial aneurysms (UIA). Studies reporting on the risk of rupture and outcomes have provided much insight, but the debate remains of how and when unruptured aneurysms should be managed. Treatment methods include two major intervention options: clipping of the aneurysm and endovascular methods such as coiling, stent-assisted coiling, and flow diversion stents. The studies reviewed here support the generalized notion that endovascular treatment of UIA provides a safe and effective alternative to surgical treatment. The risks associated with endovascular repair are lower and incur shorter hospital stays for appropriately selected patients. The endovascular treatment option should be considered based on factors such as aneurysm size, location, patient medical history, and operator experience.

Keywords: subarachnoid hemorrhage, aneurysms, endovascular surgery, coiling, clipping, stents, flow diversion

\section{INTRODUCTION}

Subarachnoid hemorrhage (SAH) is the most serious presentation of ruptured intracranial aneurysms. Autopsy reports have shown that aneurysms are present in roughly $5 \%$ of the population, yet most are often asymptomatic (Menghini et al., 1998; Iwamoto et al., 1999; Winn et al., 2002). Estimated annual incidence rates of SAH range from 10 to 15 cases per 100,000, which translates to at least 30,000 annual cases of SAH in the United States. Two-thirds of patients with aneurysm rupture either die or have a disabling neurological deficit (Stapf and Mohr, 2004). In recent years, an increasing number of unruptured, incidental aneurysms are being detected due to increased availability of noninvasive imaging modalities. While it is clear that most ruptured aneurysms must be treated to prevent rerupture, the management

\footnotetext{
Abbreviations: ATENA, analysis of treatment by endovascular approach of nonruptured aneurysms; CSF, cerebral spinal fluid; CT, computerized tomography; FDA, Food and Drug Administration; GDC, Guglielmi detachable coils; ISAT, International subarachnoid aneurysms trial.; ISUIA, The International Study of Unruptured Intracranial Aneurysms; MCA, middle cerebral artery; MRA, magnetic resonance angiography; SAH, subarachnoid hemorrhage; UIA, unruptured intracranial aneurysm; WSS, wall shear stress.
}

of the unruptured intracranial aneurysms (UIA) is more complex both from treatment decision making perspectives.

Aneurysms typically develop during adulthood and rupture risk increases with age. The mean age for aneurysmal SAH is about 50 years (Phillips et al., 1980). Typical locations at risk for the development of aneurysms are branching points (Meng et al., 2007), where structural irregularities in the collagen matrix exist (Finlay et al., 1998; Rowe et al., 2003), and elevated hemodynamic stresses due to segments involving short radii of curvature are more observed. Studies have shown that abnormal hemodynamic stress plays an important role in aneurysm formation and growth (Meng et al., 2007).

Intracranial aneurysms can be classified using several schemes. The most obvious division is considering the ruptured and unruptured lesions separately. With respect to morphology, aneurysms are classified as saccular or non-saccular. Non-saccular intracranial aneurysms such as fusiform, dolichoectatic, and dissecting aneurysms are rare with an incidence of less than $0.1 \%$ (Anson et al., 1996). Another system of classification is by aneurysm location. The predominant location for saccular aneurysms is the anterior circulation (90\%), with most arising from the circle of Willis (Bonneville et al., 2006). The anterior communicating complex (30-35\%) is the most common location, followed by the internal 
carotid artery (30\%). The basilar apex represents the most common location in the posterior circulation and accounts for $10 \%$ of all intracranial aneurysms (Bonneville et al., 2006). Aneurysms are also classified by size into subgroups of small $(<10 \mathrm{~mm})$, large $(10-25 \mathrm{~mm})$, and giant $(>25 \mathrm{~mm})$ in diameter. According to Wiebers et al. (2003), aneurysms smaller than $12 \mathrm{~mm}$ in dome size account for more than $75 \%$ of the unruptured aneurysms. The establishment of endovascular therapy has led to further classification of aneurysms based on the size of the neck. Management of UIA remains a topic of debate due to incomplete and often conflicting data relating to the natural history of aneurysms, along with the risks associated with treatment (Chen et al., 2004).

While published studies may present different aneurysm rupture risk levels, they all indicate that treatment is recommended due to the poor outcome of rupture. Ruptured aneurysms account for approximately $85 \%$ of non-traumatic SAH and are associated with a 30 -day mortality rate of $45 \%$ and a morbidity rate of $25 \%$ (van Gijn et al., 2007). In a study of hospital discharge records for patients with ruptured and unruptured aneurysms, mortality rates for SAH demonstrated little change with the introduction of endovascular treatments (Qureshi et al., 2005). In addition to poor outcomes and co-morbidities resulting from $\mathrm{SAH}$, economic burden associated with SAH must also be taken into consideration. Dodel et al. (2010) recently published a study on the cost of illness due to $\mathrm{SAH}$, the total accumulated costs in the first year were $€ 38,300$ (95\% CI, $€ 34,490$ to $€ 43,100$ ). Their data also indicate higher costs associated with younger patients. The method of treatment for ruptured intracranial aneurysms, however, remains a problem with no clear solution (Bederson et al., 2000).

\section{CEREBROVASCULAR ANATOMY AND PATHOPHYSIOLOGY OF ANEURYSMS}

It is suggested that formation of an intracranial aneurysm is a consequence of a systemic vascular pathology, which is associated with pleomorphism in different candidate genes (Toth et al., 2000; Krex et al., 2001; Yurt et al., 2010). A higher prevalence of aneurysms in the cerebrovascular system may also be due to alterations in hemodynamic and histological characteristics (Stehbens, 1990; Kondo et al., 1997; Rowe et al., 2003; Shojima et al., 2004). Cerebral arteries are particularly susceptible to aneurysm formation due to the absence of an external elastic lamina, paucity of supportive perivascular tissues, attenuated tunica media, and irregularities near bifurcations (Stehbens, 1990; Rowe et al., 2003). The internal elastic lamina is an important layer of the arterial wall, especially in the cerebral vessels. Thus, disruption of this layer would promote formation of aneurysms (Yong-Zhong and van Alphen, 1990). Particularly, the regions around the bifurcations have atypical wall structures with a discontinuity of the muscle cells of the tunica media as a medial defect in connection with a predominance of collagen fibers over the elastic ones (Rowe et al., 2003; Swietaszczyk et al., 2004). In addition to this specific structure, non-uniform collagen framework in the bifurcation region of brain arteries may further induce development of intracranial aneurysms develop (Rowe et al., 2003).

Swietaszczyk et al. (2004) demonstrated that arterial blood flow disturbance and hypertension in the brain vessels lead to increased hemodynamic stress on arterial walls. Some studies also present strong association between wall shear stress (WSS) and initiation of cerebral aneurysm formation in experimental models (Kondo et al., 1997; Shojima et al., 2004). A prolonged high WSS induces matrix metalloproteinase production and fragmentation of the internal elastic lamina at, or immediately adjacent to the apex, the bifurcation (Masuda et al., 1999; Shojima et al., 2004; Meng et al., 2007). Prolonged elevation of blood pressure leads to excessive mechanical loading and causes remodeling of the arterial wall. The exact mechanisms involved in this tissue remodeling are not completely understood, but the decreased structural integrity of the tissue may be one of the underlying reasons of aneurysm formation and growth.

\section{RISK OF ANEURYSM RUPTURE}

The International study of unruptured intracranial aneurysms (ISUIA) has been the most comprehensive clinical study of its kind to date (The International Study of Unruptured Intracranial Aneurysms Investigators, 1998). The study enrolled 4,060 patients from the US, Canada, and Europe. In phase II of ISUIA trial, there were a total of 6,221 unruptured aneurysms among different studied cohorts (i.e., operated and unoperated; Wiebers et al., 2003). A higher rupture rate was reported to be associated with larger aneurysms, location in the posterior circulation, and previous history of SAH. The 5-year cumulative rupture rate, for patients with no history of SAH and aneurysm size between 7 and $12 \mathrm{~mm}$, was 2.6 and $14.5 \%$ for aneurysms located in the anterior and posterior circulation, respectively. The greatest risk of rupture, for large size aneurysms in the posterior circulation, was 50\% (Wiebers et al., 2003). Juvela et al. (2000) followed 142 patients with 181 aneurysms for a total of 2,575 person years and reported a rupture rate of $1.46 \%$ per year (95\% CI: 1.04-2.04). Rinkel et al. (1998) presented data on nine studies, totaling 3,907 patient years and similarly concluded a rupture rate of $1.9 \%$ (95\% CI: 1.5-2.4). Prevalence of aneurysms and rupture risks were shown to increase in both studies due to the factors such as size of the unruptured aneurysm, age of the patient, pre-existing familial conditions, and hypertension. Smoking has been also associated with higher prevalence aneurysms and rate of rupture (Juvela et al., 2001). More recent studies have begun to focus on additional quantification methods of aneurysms to predict rupture risks. Several geometric indices, measured by using three-dimensional rotational angiography or digital subtraction angiography, have correlated to increased rupture rates. Ryu et al. (2010) compared geometric indicators of 109 unruptured and 105 ruptured aneurysms to develop imaging predictor markers of aneurysm rupture. The two highest indicators were the aspect ratio (the ratio of the aneurysm's height to its neck) and the volume to neck ratio. From the published data in the literature, larger aneurysms have an increased risk of rupture. Raghavan et al. (2005) noted that two other factors, the undulation index and the non-sphericity index, are strong predictors of aneurysm rupture as well.

\section{TREATMENT OPTIONS \\ SURGICAL CLIPPING}

The first direct operation on an intracranial aneurysm was performed by Norman Dott in 1931 (Dott, 1933). In 1937, Walter Dandy performed the first operation for clipping an intracranial 
aneurysm, in which he applied a silver clip across the neck of a posterior communicating artery aneurysm (Chyatte, 1996; Chicoine, 2003). Introduction of operative microscopes, development of dedicated aneurysm clips, and development of advanced surgical approaches were instrumental to improving outcomes from aneurysm surgery. Factors such as site, size, and age-specific risks of repair for each patient should be considered in the treatment of UIA (Wiebers et al., 2003).

A detailed description of open surgical technique for aneurysm clipping is beyond the scope of this review. Some important steps include patient positioning, planning of the craniotomy, and a microsurgical approach to clipping of the aneurysm. Depending on the location of the aneurysm, specific arachnoidal dissection is necessary to obtain proximal control of the parent artery. Once this is achieved, the aneurysm can be exposed and dissected under high magnification. The middle cerebral artery (MCA) bifurcation aneurysms serve as examples of the various approaches available.

There are three different approaches to expose the MCA aneurysm in the sylvian fissure. The sylvian fissure can be opened from medial (proximal) to lateral (distal) or vice versa. The lateral to medial approach requires less brain retraction and is usually more direct to these superficial aneurysms (Roberts and Dacey, 2004). Alternatively, an incision in the superior temporal gyrus with subpial resection can be used to expose the aneurysm (Ogilvy et al., 1995). This approach may be particularly useful when there is an associated temporal lobe hematoma. Thereafter, routinely the parent artery is prepared for temporary clipping before deployment of the permanent clips (Chyatte and Porterfield, 2001). Temporary clipping of the parent artery is useful in the event of an intraoperative aneurysm rupture. Moreover, it is useful to reduce the turgor of the aneurysm and facilitate permanent clip application across the aneurysm neck. However, there may be a higher risk of ischemic complications with temporary clipping (Lavine et al., 1997). Prior to temporary clipping, blood pressure may be elevated pharmacologically and cerebral protectants such as barbiturates, propofol, or etomidate can be administered to reduce the risk of ischemia. Finally, after placement of the permanent clip on the aneurysmal neck, intraoperative micro-Doppler, non-invasive near infrared indocyanine green videoangiography, or invasive intraoperative cerebral angiography are employed to assess the patency of the parent artery as well as the entire occlusion of the aneurysm neck (Raabe et al., 2005; Dashti et al., 2007). A case of clipping of a right MCA aneurysm is illustrated in Figure 1.

\section{ENDOVASCULAR COILING}

In 1939, the first endovascular treatment of an intracranial aneurysm was performed, in which 30 feet of silver wire were placed into a giant cavernous carotid aneurysm that had eroded the orbit (Werner et al., 1941). In Luessenhop and Velasquez (1964) first described catheterization of the intracranial arteries and catheter based embolization of an intracranial aneurysm. In the early 1970s, Serbinenko (1974), considered by many to be the founder of endovascular neurosurgery, developed a series of balloon mounted flow guided catheters and detachable balloons designed to occlude intracranial vascular lesions. In the 1980s and early 1990s, Guglielmi et al. (1991a,b) combined the concepts of electrothrombosis and endovascular approaches to develop a detachable coil system. Guglielmi detachable coils (GDC) were approved by the Food and Drug Administration (FDA) and form the basis of contemporary endovascular treatment of intracranial aneurysms. Endovascular therapy for aneurysms is attractive because an effective and often equivalent result can be achieved with a less invasive method compared to traditional microsurgery. This may result in decreased hospitalization and faster recovery times for the patient (Johnston, 2000; Higashida et al., 2007).

The following is an overview of the key steps of the coil embolization procedure. The procedure can be performed under general anesthesia or conscious sedation depending on the patient's ability to cooperate, the complexity of the aneurysm, and the operator's preference. Aneurysm coiling is typically performed using biplane fluoroscopic guidance. A typical procedure involves gaining access to the common femoral artery and navigating a guide catheter, ranging from 5 to 7 French in diameter, into the internal carotid artery or vertebral artery. A microcatheter, ranging in size from 1.7 to 2.3 French, is then advanced over a microwire (typically $0.014^{\prime \prime}$ ). Once the best projection of the aneurysm is obtained (i.e., a view that clearly delineates the aneurysm neck and surrounding arterial branches), the microcatheter is advanced into the aneurysm. Platinum coils of various configurations and sizes are deployed and detached through the microcatheter. The coils are detached using either a hydraulic or electrolytic mechanism.

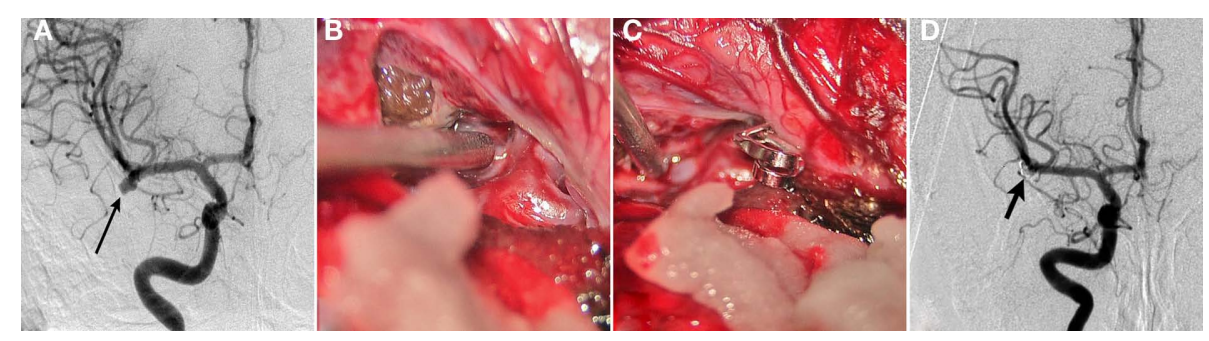

FIGURE 1 | Clipping of MCA aneurysm. A 49-year-old woman presented with subarachnoid hemorrhage. (A) Cerebral angiography demonstrated a 6-mm right MCA bifurcation aneurysm. Like most MCA aneurysms, this lesion had a wide neck involving the origins of the insular (M2) MCA divisions.
(B) A right frontotemporal craniotomy and sylvian fissure opening was performed with microsurgical exposure of the aneurysm. (C) A single clip was applied across the aneurysm neck. (D) Postoperative angiography confirmed complete clipping (arrows) of the aneurysm. 
In general terms, the first coil is either sized or slightly undersized to the maximum diameter of the aneurysm. For example, a 7-mm coil would be a reasonable first coil for a 7.3-mm diameter aneurysm. After framing coils are placed, the subsequent coils are two-dimensional "filling" or "finishing" coils. Additional coils are deployed until the aneurysm is no longer filling with contrast or until additional coils cannot be placed safely. The latter condition is often represented by either the final coil or the microcatheter protruding into the parent artery. There are a variety of microcatheters, microwires, and coils available in the market. The choice of device depends on the vascular tortuosity, the navigability and stability of the catheter, and ultimately operator preference. Up to 2004 , more than 125,000 patients with ruptured and unruptured aneurysms had been treated with the GDC system (Pereira, 2003). Figure 2 illustrates a case study of coil embolization procedure for an aneurysm.

The early experience with coiling tended to be limited to aneurysms with narrow necks. Wide necked aneurysms, defined from an endovascular standpoint as those with a dome-to-neck ratio $>2$ or an absolute neck diameter $>4 \mathrm{~mm}$, were not amenable to coil embolization until technological advancements in the late 1990s and early 2000s. Three major advancements have expanded the indications for coil embolization of these wide-neck aneurysms. First, the introduction of three-dimensional coils has allowed for complex framing configurations to be achieved with less coil protrusion into the parent artery. Second, the development of balloon assisted coil embolization has allowed for improved packing density of coils and also reduces the risk of coil protrusion into the parent vessel. In this technique, a compliant balloon is navigated and inflated across the neck of an aneurysm as coils are introduced into the aneurysm through the microcatheter. The balloon can also arrest flow in the parent artery in the event of an intraprocedural aneurysm rupture (an example of balloon assisted coil embolization is shown in Figure 3). Finally, stent-assisted coil embolization has allowed for treatment of the very wide necked aneurysms and diffusely diseased segments of arteries. The microcatheter can be navigated through the pores of the stent into the aneurysm or can be trapped between the artery wall and the stent. In addition to improving coil packing density and preventing coil protrusion, the stent may divert flow away from the aneurysm and allow vessel remodeling. Currently available stents include Enterprise stent system (Codman, J\&J, Raynham, MA, USA) and Neuroform stent system (Stryker, Kalamazoo, MI, USA).

Murayama et al. (2003) described a single center experience with GDCs during an 11-year period from 1990-2002. A total of 916 aneurysms in 818 patients were treated by coiling and results were separated into patients treated before and after FDA approval of coils. This study included patients with acute SAH (49\%), unruptured aneurysms (42\%), and non-acute SAH (9\%). Three hundred thirty-four aneurysms (36.5\%) were small, 198 $(21.6 \%)$ were large, $73(8 \%)$ were giant. The overall results were complete occlusion in 504 (55\%) of 916 aneurysms, and a neck remnant was seen in 234 (35.4\%). Complete occlusion was highest $(86.2 \%)$ in small diameter and small neck aneurysms, the occlusion rate was reduced by approximately half in the other groups, which subsquenlty had increases in the amount of neck remants. Another study by Gonzalez et al. (2004), examined 247 UIA treated at the UCLA Medical Center during a similar time period (19912000). Of those UIA's, 118 (54.4\%) were found incidentially during angiography, CT angiography, or MR angiograghy, and 51 (23.5\%) presented with mass effect. Angiographic results indicate complete occlusion was achieved in 138 (55\%) of 247 aneurysms, incomplete occlusion in $3(1.2 \%)$, and neck remnants in $92(37.2 \%)$. Further evaulation of the results, stratified into the aneurysm size groups described in the Murayama et al. (2003) study, show higher success rates for complete occlusion in smaller aneurysms. Of the 83 small aneurysms with narrow necks, 63 (75\%) were completely occluded, while $20(23.8 \%)$ had a neck remnamt. As aneurysm size increased, the likeliness of complete occlusion was greatly reduced, with success being achieved in 7 (24.1\%) of 29 giant aneurysms. Wanke et al. (2002) published endovascular treatment results of 39 patients harboring 42 unruptured aneurysms. The study included 18 small $(0-5 \mathrm{~mm}), 11$ medium $(6-10 \mathrm{~mm}), 9$ large $(11-25 \mathrm{~mm})$, and 4 giant $(>25 \mathrm{~mm}$ ) aneurysms. Endovascular treatment was

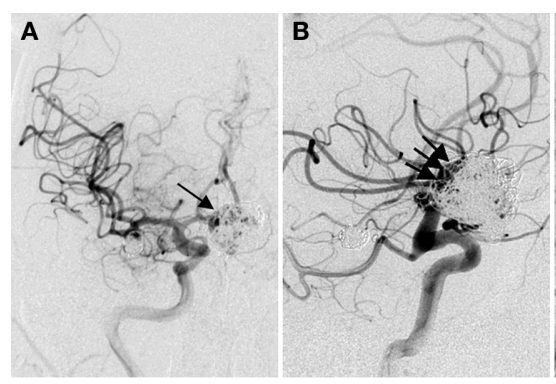

FIGURE 2 | Recanalized aneurysm. A 59-year-old man presented with $\mathrm{SAH}$ found to have multiple aneurysms including a giant anterior communicating artery (ACOA) aneurysm. He underwent primary coil embolization initially. (A) Anterior-posterior (AP) view of a right ICA injection shows coil mass in the giant aneurysm (arrow). There is still some residual filling of the aneurysm. (B) Lateral view shows the residual aneurysm more clearly (arrows). The anterior cerebral arteries (ACA) were difficult to separate from the aneurysm on the angiogram, and the aneurysm was underpacked in order to preserve these arteries. Follow-up angiography was

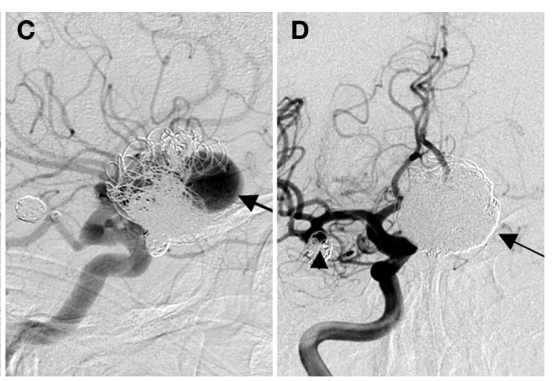

performed 6 months after the patient made a good neurological recovery. (C) Lateral view of the right ICA injection shows significant recanalization of the dome of the aneurysm (arrow). (D) The patient underwent retreatment of the aneurysm with stent placement from the $A 1$ segment of the right ACA into the A2 segment of the left ACA. This was followed by additional coil placement including gel coated coils. Subtracted view of the right ICA injection shows a dense coil mass in the giant aneurysm (arrow). Also note some recanalization of the right MCA aneurysm neck (arrowhead) 
deemed technically feasbible in 38 aneurysms, with 4 being unable to be treated due to an unfavorable dome-to-neck ratio. They reported complete $(100 \%)$ or near complete (95-99\%) occlusion in $34(89.5 \%)$ aneurysms. Incomplete occlusion $(<95 \%)$ was achieved in four aneurysms (three large and one giant).

While endovascular coiling of intracranial aneurysms has offered an alternative treatment option to open surgery, there are serious risks to consider. Some of these risks overlap with those seen in open surgery and others are unique to endovascular therapy. Murayama et al. (2003) reported procedural complications in $69(8.45 \%)$ patients, the most common being thromboembolism in $24(2.4 \%)$ patients. This percentage is also similar to the cerebral embolization reported by Gonzalez et al. (2004); 3.7\%). Other complications include aneurysm perforation, parent artery occlusion, coil migration, arterial dissection, and vasospasm.

A major shortcoming of aneurysm coiling, especially in the early era of the therapy, was durability. The main etiology for recanalization is coil compaction. Another mechanism may be rearrangement of individual coil loops. Insufficient packing of the aneurysm neck increases the chances of aneurysm recurrence (Raymond and Roy, 1997). The ability to increase packing density has improved with the introduction of three-dimensional coils and hydrogel coated coils that swell when exposed to blood. The clinical relevance of aneurysm recanalization for endovascluar approach is not settled unless rerupture risks for coiled aneurysms and surgical clipping are comparable. Clinical outcomes of aneurysm coiling are superior for small to medium size aneurysms when compared to giant and fusiform aneurysms. A review of 46 studies encompassing 8,161 coiled aneurysms showed a $91 \%$ rate of adequate occlusion at initial treatment (Ferns et al., 2009). Recanalization was reported in $21 \%$ of aneurysms, and retreatment was performed in $10 \%$.

In summary, complete or near complete occlusion at initial treatment with endovascular coiling in small aneurysms seems to trend toward a durable result that compares favorably with the durability of clipping. The risk of subsequent invasive procedures must be included when considering the initial treatment of

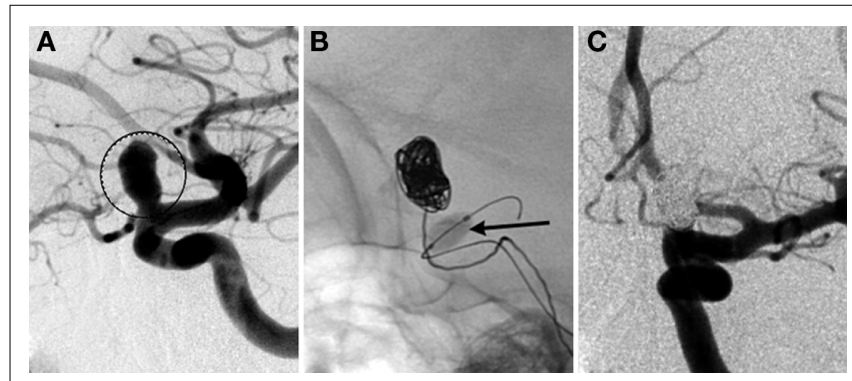

FIGURE 3 | Balloon assisted coil embolization. A 74-year-old man with a strong family history of aneurysmal SAH was found to have a left ophthalmic aneurysm. (A) Lateral view of a left ICA injection shows a 7.5-mm left ophthalmic artery aneurysm (circled) with a 4.2-mm neck. The patient underwent balloon assisted coil embolization. (B) Lateral fluoroscopic view shows the inflated balloon (arrow) with coils being deployed through a microcatheter within the aneurysm. (C) AP view of the final left ICA injection shows no residual aneurysm. an intracranial aneurysm. At our institution, we typically perform at least one follow-up angiogram at 6 months. The results of the follow-up angiogram determine the need for additional angiograms. We have also found magnetic resonance angiography (MRA) to be a useful alternative in detecting recanalization in some cases.

\section{STENT-ASSISTED COILING}

Stents have been developed as an endovascular approach to open blocked arteries in patients for re-establishing normal blood flow to tissue at risk. The first coronary stent was implanted in a human in 1986, and by 1999 its use had increased to $83 \%$ of all endovascular interventions in the coronary arteries (Holmes et al., 2002). The early stents were made of stainless steel and were deployed using a balloon catheter to mechanically force open the vessel to increase blood flow. The evolution of coronary stents eventually led to selfexpanding stents eliminating the need for balloon angioplasty to expand the stent against the arterial wall. Material advances also led to the development of stents comprised of super-elastic metals. The combination of these two technologies enabled stents to be extremely flexible and expand without the use of rigid balloon catheters, which in turn reduces the tendency of vessel rupture due to arterial wall damage during deployment. These improvements, in conjunction with the introduction of microcatheters and microwires, enabled clinicians to navigate and deliver stents to previously inaccessible areas, more specifically the cerebral vasculature. The first stent designed for treatment of aneurysms was the Neuroform stent, which received a Humanitarian Device Exemption from the FDA in late 2002 (Fiorella et al., 2005). The primary objective of a stent application is to provide a scaffold for coiling an aneurysm with difficult shapes and sizes with a wide neck. A case report of a stent-assisted coil embolization is described in Figure 4 .

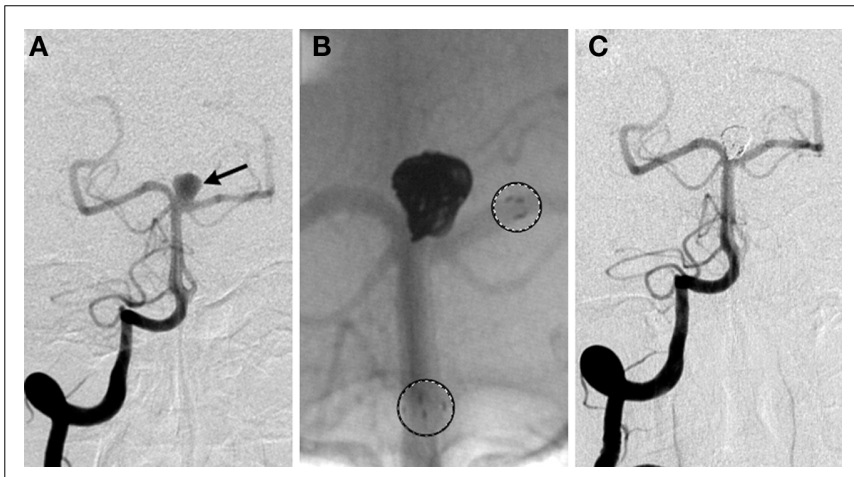

FIGURE 4 | Stent-assisted coil embolization. A 64-year-old woman with headaches and a family history of aneurysms underwent screening and a basilar apex aneurysm was discovered. (A) AP view of a right vertebral artery (VA) injection demonstrates the wide neck aneurysm (arrow). The neck incorporates the origin of the left posterior cerebral artery (PCA). (B) A Neuroform stent (Boston Scientific, Natick, MA, USA) delivery system positioned with the proximal and distal markers (circles) visible on fluoroscopy. Coils were introduced into the aneurysm through a separate microcatheter. (C) Final AP view shows near total occlusion of the aneurysm and preservation of the left PCA. 
Table 1 | Immediate anatomical results from stent-assisted coiling studies.

\begin{tabular}{lclll}
\hline Author & $\begin{array}{l}\text { Aneurysms } \\
\text { treated }\end{array}$ & $\begin{array}{l}\text { Complete } \\
\text { occlusion }\end{array}$ & $\begin{array}{l}\text { Neck } \\
\text { remnant }\end{array}$ & $\begin{array}{l}\text { Remnant } \\
\text { aneurysm }\end{array}$ \\
\hline Fiorella et al. (2005) & 61 & $28(45.9 \%)$ & NA & $33(54.1 \%)$ \\
Lubicz et al. (2008) & 15 & $8(53.3 \%)$ & $4(26.7 \%)$ & $3(20.0 \%)$ \\
Lubicz et al. (2009) & 34 & $9(26.5 \%)$ & $2(6.0 \%)$ & $23(67.5 \%)$ \\
Weber et al. (2007) & 31 & $6(19.3 \%)$ & $18(58.1 \%)$ & $7(22.6 \%)$ \\
Vendrell et al. (2011) & 50 & $18(36.0 \%)$ & $14(28.0 \%)$ & $18(36.0 \%)$ \\
Biondi et al. (2007) & 40 & $14(35.0 \%)$ & $18(45.0 \%)$ & $8(20.0 \%)$ \\
Piotin et al. (2010) & 216 & $100(46.3 \%)$ & $41(19.0 \%)$ & $75(34.7 \%)$ \\
Pierot et al. (2008) & 53 & $23(43.4 \%)$ & $11(20.8 \%)$ & $19(35.4 \%)$ \\
Total & 500 & 206 & 108 & 186 \\
\hline
\end{tabular}

Table 1 shows the outcomes of stent-assisted coiling studies. Fiorella et al. (2005) were among the earliest to report results from stent-assisted coiling immediately following the FDA limited approval use of the device for broad-neck, fusiform, or giant aneurysms. The study included a total of 74 aneurysms in 64 patients, however only 61 aneurysms were treated with stentassisted coiling. Follow-up angiographic (average 4.6 months) results were available for 48 aneurysms. Eleven patients showed an increase in residual aneurysm size, seven of which underwent additional coil embolization. Residual aneurysm decreased or resolved in 25 patients, while no change was observed in 12 patients. Similar results were shown by Lubicz et al. (2008) who treated 15 unruptured aneurysms in 14 patients with stent-assisted coiling. All patients showed excellent (neurologically intact) clinical outcome after the procedure. Lubicz et al. (2009) published another study, utilizing the Leo stent (Balt, Montmorency, France) and Enterprise stent (Codman, J\&J, Raynham, MA, USA), on long term follow up of patients treated with stent-assisted coiling. Thirty-four aneurysms, all wide-neck (neck $>4 \mathrm{~mm}$ or neck/sac ratio $>0.7$ ), were treated in 32 patients. Follow up was performed at 6 months ( $n=4$ patients), 12 months ( $n=16$ patients), and 36 months ( $n=12$ patients) with a mean of 20 months. Final angiographic results (performed between 6 and 36 months) showed aneurysm occlusion was complete in 27 (79\%), neck remnant in 3 (9\%), and incomplete in 4 (12\%).

Favorable results were also shown by Weber et al. (2007) for the treatment of 31 wide-neck saccular aneurysms in 30 patients. Successful stent placement with adequate coil positioning, without any procedural complications, was achieved in $28(90 \%)$ of 31 aneurysms. At 6 months, they observed complete occlusion in $15(50 \%)$ aneurysms, neck remnants in 8 (26.7\%) aneurysms, and $7(23.3 \%)$ residual aneurysms. Results also revealed that 29 $(93.5 \%)$ of the parent arteries were unaffected, while 2 parent vessels had minor asymptomatic narrowing at the stent site. Vendrell et al. (2011) assessed stent-assisted coiling in 49 patients presenting a total of 52 unruptured MCA aneurysms. Fifty (96.2\%) aneurysms were successfully treated; two were referred to surgery after catheterization of the parent vessel was unsuccessful. At a follow-up period of $14 \pm 9$ months, complete treatment was observed in $34(71 \%)$ aneurysms, residual necks were present in $6(12 \%)$, and incomplete occlusion in $8(17 \%)$. Biondi et al.
(2007) reported retrospective results of stent-assisted coiling in the treatment of 46 wide-neck aneurysms in 42 patients, however only 40 aneurysms were successfully treated with stents and coils. Follow-up results of 30 aneurysms treated by stent-assisted coiling showed 17 (57\%) aneurysm occlusions, 7 (23\%) presented neck remnants, and $6(20 \%)$ had a residual aneurysm. A recent study published by Piotin et al. (2010) presented results on the endovascular repair of 1,325 aneurysms using coils, including 216 that were treated by stent-assisted coiling. One hundred eighty-one $(83.8 \%)$ of the aneurysms receiving a stent were unruptured. The analysis of angiographic follow up showed that stented aneurysms hade lower recurrence rates vs. non-stented aneurysms. The study showed the use of stents was beneficial in terms of angiographic stability in both ruptured $(P=0.0339)$ and unruptured $(P=0.0073)$ aneurysms.

The analysis of treatment by endovascular approach of nonruptured aneurysms (ATENA), published by Pierot et al. (2008), has been one of the most comprehensive studies on the treatment of unruptured aneurysms. The study included 649 patients, harboring 739 aneurysms. Seven hundred twenty-seven aneurysms were treated using coils $(98.4 \%)$. Coils alone were used in 396 aneurysms (54.4\%), with balloon remodeling in 271 cases $(37.3 \%)$, intracranial stents in 57 cases $(7.8 \%)$, and the Trispan neck bridge in 3 cases $(0.4 \%)$. Treated aneurysms were divided into four size categories; 131 (17.7\%) aneurysms were $1-3 \mathrm{~mm}, 304(41.1 \%)$ aneurysms were 4-6 mm, 215 (29.1\%) aneurysms were 7-10 mm, and $89(12.0 \%)$ aneurysms were $11-15 \mathrm{~mm}$. Fusiform and dissecting aneurysms were excluded from the study, as well as patients who had experienced a SAH from another aneurysm within the last month. Initial results indicated postoperative occlusion was complete in 436 aneurysms (59.0\%); neck remnant in 160 aneurysms (21.7\%), and aneurysm remnant in 143 aneurysms (19.3\%). Another study by Pierot et al. (2010) further broke down the analysis of the ATENA results for each treatment technique. The outcomes based on treatment techniques are shown in Table 2. The ATENA study shows the viability of endovascular treatment of unruptured aneurysms can be achieved in large number of cases $(95.7 \%)$ with low mortality and morbidity (1.4 and $1.7 \%$, respectively).

Stent-assisted coiling has improved the ability to treat difficult and complicated aneurysms since its FDA approval in 2002. New clinical techniques continue to emerge along with advances in-stent design. However, while these devices provide another treatment option for endovascular repair, additional risks are associated with stent placement compared to coiling alone. Placing a stent in the parent artery requires lifetime use of antiplatelet agents to reduce the risk of thrombosis based stenosis within the stent. Kanaan et al. (2010) reported acute in-stent thrombosis or chronic stenosis in 9 of 133 stent-coil deployments $(6.8 \%)$ during a mean follow up of 15.4 months. The need for anti-platelet therapy limits the role of stent placement in patients with ruptured aneurysms. These patients may need additional invasive procedures such as ventriculostomy, decompressive craniectomy, tracheostomy, or gastrostomy. The risk of these procedures is increased due to anti-platelet or anticoagulation therapy. Mocco et al. (2009) showed a high rate of mortality in patients with SAH when compared to the unruptured 
Table 2 | Immediate anatomical results by treatment technique, ATENA study (Pierot et al., 2010).

\begin{tabular}{llll}
\hline Anatomical results & Coiling & Remodeling & Stenting \\
\hline Complete occlusion & $244(63.7 \%)$ & $170(65.9 \%)$ & $23(43.4 \%)$ \\
Neck remnant & $85(22.2 \%)$ & $60(23.3 \%)$ & $11(20.8 \%)$ \\
Remnant aneurysm & $54(14.1 \%)$ & $28(10.9 \%)$ & $19(35.8 \%)$ \\
Total & $383(100 \%)$ & $258(100 \%)$ & $53(100 \%)$ \\
\hline
\end{tabular}

cohort ( 12 vs. $0.8 \%$, respectively). In the study reported by Piotin et al. (2010), mortality rates were similarly high (6.0 vs. $1.2 \%$ in aneurysms treated with stent and without stent, respectively). Differences in procedural complications were also statistically significant $(P=0.027)$ when comparing results of aneurysms treated with stent $(7.4 \%)$ and those treated without a stent $(3.8 \%)$. The increase in complications translated into higher procedure related deaths (4.6 to $1.2 \%, P=0.006$ ). Long term studies are needed to further evaluate in-stent thrombosis or stenosis. Due to their high porosity, stents surface area coverage of aneurysm neck is relatively low (4 to $7 \%$ ). Therefore while they may provide improved stability for coiling, they are not sufficient as a stand-alone therapy of the majority of intracranial aneurysms.

\section{FLOW DIVERSION}

With advent of computational fluid dynamics over the past few decades, more and more research has begun focusing on advancing aneurysm treatment options. Improvement in imaging modalities has greatly influenced medical device design. The latest neuroendovascular devices for treating intracranial aneurysms to reach the market are flow diverters. So far, limited clinical approval has been achieved on any such device, but procedures are performed under FDA exemption for compassionate use (Fiorella et al., 2008). The primary goal of a flow diversion device is to divert flow away from the aneurysm by placing a mesh structure, similar to a stent, on the aneurysm neck along the parent artery. By decoupling blood flow between the parent artery and aneurysmal sack, a flow diverter can create blood stasis to allow for thrombus formation inside the aneurysm. Flow diverters are intended to be used in anatomical situations where stent-assisted coiling becomes difficult, such as giant or fusiform aneurysms. In terms of design, they are very similar to stents, consisting of a highly flexible tubular structure with a mesh. They differ in one major aspect, the porosity of the cells or mesh is less than typical stents. Therefore, the major focus in manufacturing design for flow diverters has been shift from radial force exerted by the stent on the vessel wall to flow alternation inside the aneurysm (from solid mechanics to fluid mechanics). These scaffolds, or constructs, are specifically designed for use in the neurovasculature, where as stent design evolved from its original coronary application.

Lylyk et al. (2009) were among the first to report large clinical results on the use of flow diverters in 53 patients harboring 63 aneurysms. Immediate angiographic results showed only 5 of 63 (8\%) were completely occluded, all of which were small $(<10 \mathrm{~mm})$ aneurysms. Complete angiographic occlusion was achieved in
$56 \%$ at 3 months $(n=42), 93 \%$ at 6 months $(n=28)$, and $95 \%$ at 18 months $(n=18)$ follow up. Szikora et al. (2010) reported results for 19 wide-neck aneurysms in 18 patients; however their study included 10 aneurysms treated with coil packing in addition to the use flow diverters. Six month follow up of 18 aneurysms revealed 17 complete occlusions.

Kulcsar et al. (2010) reported the use of flow diversion devices in 12 basilar artery aneurysms. Short term (<32 weeks) follow up indicated that 7 of $12(58 \%)$ of the treated aneurysms had completely occluded. Lubicz et al. (2010) successfully delivered a flow diverter device in 26 of 29 (90\%) patients harboring 34 unruptured aneurysms. Mortality and morbidity rates were $4 \%$ ( 1 of 26 ) and $15 \%$ (4 of 26), respectively. Immediate anatomic outcomes, assessed by angiographic imaging, included complete stasis in 4 aneurysms (12.9\%), significant flow reduction in 13 aneurysms $(41.9 \%)$, slow flow in 13 aneurysms (41.9\%), and unchanged flow in 1 aneurysm. Follow-up angiographic results were available in 24 patients with 29 aneurysms at $6(n=12)$ and $12(n=12)$ months. Results showed 20 complete occlusions (69\%), 1 neck remnant (3.5\%), and 8 incomplete occlusions (27.5\%). Byrne et al. (2010) collected data for 70 patients where 60 patients were treated by flow diversion device only, and 10 were treated with a flow diverter and coils combination. Angiographic assessment at the end of treatment, for the 68 successful interventions (in 67 patients), showed complete occlusion in $7(10 \%)$, neck remnant in $4(6 \%)$, and residual sac filling in 57 (84\%). They reported follow-up angiography in $49(72 \%)$ aneurysms, all but 2 showed no change or improvement.

Current research continues to materialize on the use of flow diverters to treat intracranial aneurysms. These devices are typically deployed in situations where established techniques, such as coiling and stent-assisted coiling, are not viable options. It is not surprising that with increased technical demands, comes increased technical complications with deployment of flow diverters. Lubicz et al. (2010) reported an overall complication rate of $38 \%$, including parent artery stenosis, distal embolism, in-device thrombosis, branch occlusion, and hemorrhage or mass effects. They also reported parent artery stenosis in eight cases (33\%) at follow up. In another study, parent artery occlusion was seen in seven (14\%) patients, with additional arterial narrowing in three (6\%) patients (Byrne et al., 2010).

Stents used for coil stability do not substantially reduce blood flow to the aneurysm sack as compared to flow diverters. Clinicians must use caution in deployment of flow diverters when aneurysms are located near regions of side branching arteries. Incorrect placement could prevent blood flow to an otherwise healthy artery. Another concern with flow diverters is the low porosity, needed to reduce blood flow, will be problematic if additional coiling is needed after deployment due to the small open spaces in the mesh. Anti-coagulants required for flow diverters may be beneficial for prevention of in-device thrombus, but could negatively impact the time for thrombus formation inside the aneurysm without the additional coil packing used with stents. The interaction of thrombus formation inside aneurysms is not clearly understood and has been suggested it could lead to rupture after deployment of a flow diverter (Kulcsar et al., 2011). The 
mechanisms behind this phenomenon could relate to a reduction in WSS below normal physiological values (Boussel et al., 2008), leading to vessel remodeling and rupture. Endovascular treatment of intracranial aneurysms using flow diverters is a relatively novel approach, with a small number of clinical results available, and more information is needed to fully evaluate the effectiveness. It should be noted that Pipeline Embolization Device (PED), owned by Covidien, Mansfield, MA, USA (previously owned by eV3, Inc./Chestnut Medical Technologies, Inc., Menlo Park, CA, USA) has recently been approved by the FDA Neurological Devices Advisory Panel as flow diversion device for treatment of aneurysms, and is currently awaiting a final decision by the FDA committee.

\section{COMPARISON OF SURGICAL CLIPPING AND COIL EMBOLIZATION}

The advent of endovascular therapy has certainly reduced the role of open surgery. For some aneurysms, endovascular treatment is preferred, whereas for others surgery is still superior in both cost and outcomes (Chicoine, 2003; Takao and Nojo, 2007). The choice of open surgery vs. endovascular surgery for aneurysms, whether ruptured or unruptured, remains an individualized decision. The following factors play a role in treatment decision making: (1) age, past medical history, and medical/neurological conditions help to determine the patient's ability to tolerate a specific treatment. For example, a patient with a ruptured aneurysm in poor neurological condition likely has a diffusely swollen, friable brain, and coil embolization may be superior to surgery in this setting. On the other hand, a young patient with an unruptured aneurysm may be a good candidate for open surgery in anticipation of achieving a durable result. In some instances, patient preference also plays a role in which treatment is chosen. (2) Aneurysm characteristics such as location (suitability for surgical access), morphology, and size. Basilar apex aneurysms are associated with higher surgical morbidity compared to other locations, so endovascular treatment is usually the preferred choice of treatment. On the other hand, MCA aneurysms tend to have complex morphologies with wide necks and important arterial branches may be incorporated into the aneurysm. These aneurysms tend to be more suitable for open surgery. A ruptured aneurysm with a large intracerebral hematoma and mass effect may be better suited for surgery. (3) Finally, operator preferences are often understated but equally important. This includes the operator's bias toward a certain treatment because of experience and familiarity. Some complex aneurysms may require a combination of open and endovascular surgeries.

The International subarachnoid aneurysms trial (ISAT) was a randomized, multicenter study that compared clinical outcomes of patients presenting with ruptured aneurysms, and treated either by clipping or by coiling (Molyneux et al., 2002). A total of 9,559 patients with SAH were assessed, and 2,143 patients were ultimately enrolled and randomized. Initial clinical outcomes from ISAT indicated little difference between endovascular and surgical treatment. However, the results at 1 year follow up were convincing enough to lead to an early termination of the study, because those treated with endovascular coiling had a $6.9 \%$ absolute risk reduction and $22 \%$ relative risk reduction in poor outcome compared with surgical clipping (Molyneux et al., 2002). Long term follow ups in ISAT indicated endovascular coiling had a higher risk of rebleeding than clipping, but the risk was low and remained similar to risk of SAH from another aneurysm (Molyneux et al., 2009). The ISAT study indicated that endovascular treatment was a safe and effective alternative to surgical treatment for certain ruptured aneurysms. However, the results were not sufficient to determine that endovascular treatment is superior to surgical treatment in all patients with ruptured aneurysms and cannot be applied to unruptured aneurysms. The trial demonstrated that coil embolization resulted in less peri-procedural morbidity in a selected group of patients. Retreatment was performed in $17.4 \%$ of the 1,096 patients who underwent endovascular therapy and in $3.8 \%$ of the 1,012 patients who underwent surgical clipping (Campi et al., 2007).

A recent study reported by Alshekhlee et al. (2010) compared hospital mortality and complication rates associated with aneurysm clipping and coiling based on the National Inpatient Sample (NIS) between 2000 and 2006. A total of 3,738 patients had aneurysm clipping and 3,498 had endovascular coiling. For clipping vs. endovascular coiling, both median length of hospital stay (4 and 1 days, respectively, $P<0.0001$ ) and mortality ( 1.6 vs. $0.57 \%$, respectively) were higher. The study also presented data showing a trend in hospital use of endovascular coiling has increased during recent years. Singh et al. (2002) showed that increased clinician experience with endovascular coiling resulted in decreased risk of complications. The combination of these factors may be advantageous for endovascular treatment were similar comparative studies to be conducted.

\section{DISCUSSION}

Advances in imaging modalities and knowledge of natural history and prevalence of aneurysms have increased detection of unruptured asymptomatic intracranial aneurysms. An unbiased assessment of most appropriate course of treatment is crucial for achieving a favorable outcome. The size of an aneurysm has been associated with higher risk of complications for both surgical and endovascular treatment approach (Johnston et al., 2002). Studies reporting on the risk of rupture and outcomes have provided much insight but the debate remains of how and when unruptured aneurysms should be managed. The studies reviewed here support the generalized notion that endovascular treatment of UIA provides a safe and effective alternative to surgical treatment. The risks associated with endovascular repair are lower and incur shorter hospital stays for appropriately selected patients. The method of endovascular treatment should be considered based on factors such as aneurysm size, location, patient medical history, and clinician experience. To date, there have been no randomized large studies comparing outcomes using different endovascular options. The likeliness of such a study appears slim as the variability in the use of devices is wide. Furthermore, the rapid development of endovascular technology often prevents adequate appraisal of existing devices and methods. Currently, endovascular therapy and surgical therapy must be viewed as complementary rather than competitive in the treatment of intracranial aneurysms. 


\section{REFERENCES}

Alshekhlee, A., Mehta, S., Edgell, R. C., Vora, N., Feen, E., Mohammadi, A., Kale, S. P., and CruzFlores, S. (2010). Hospital mortality and complications of electively clipped or coiled unruptured intracranial aneurysm. Stroke 41, 1471-1476.

Anson, J. A., Lawton, M. T., and Spetzler, R. F. (1996). Characteristics and surgical treatment of dolichoectatic and fusiform aneurysms. J. Neurosurg. 84, 185-193.

Bederson, J. B., Awad, I. A., Wiebers, D. O., Piepgras, D., Haley, E. C. Jr., Brott, T., Hademenos, G., Chyatte, D., Rosenwasser, R., and Caroselli, C. (2000). Recommendations for the management of patients with unruptured intracranial aneurysms: a statement for healthcare professionals from the stroke council of the american heart association. Stroke 31, 2742-2750.

Biondi, A., Janardhan, V., Katz, J. M., Salvaggio, K., Riina, H. A., and Gobin, Y. P. (2007). Neuroform stent-assisted coil embolization of wide-neck intracranial aneurysms: strategies in stent deployment and midterm follow-up. Neurosurgery 61, 460-468; discussion 468-469.

Bonneville, F., Sourour, N., and Biondi, A. (2006). Intracranial aneurysms: an overview. Neuroimaging Clin. N. Am. 16, 371-382, vii.

Boussel, L., Rayz, V., McCulloch, C., Martin, A., Acevedo-Bolton, G., Lawton, M., Higashida, R., Smith, W. S., Young, W. L., and Saloner, D. (2008). Aneurysm growth occurs at region of low wall shear stress: patient-specific correlation of hemodynamics and growth in a longitudinal study. Stroke 39, 2997-3002.

Byrne, J. V., Beltechi, R., Yarnold, J. A., Birks, J., and Kamran, M. (2010). Early experience in the treatment of intra-cranial aneurysms by endovascular flow diversion: a multicentre prospective study. PLoS ONE 5, e12492. doi: 10.1371/journal.pone.0012492

Campi, A., Ramzi, N., Molyneux, A. J., Summers, P. E., Kerr, R. S., Sneade, M., Yarnold, J. A., Rischmiller, J., and Byrne, J. V. (2007). Retreatment of ruptured cerebral aneurysms in patients randomized by coiling or clipping in the international subarachnoid aneurysm trial (isat). Stroke 38, 1538-1544.

Chen, P. R., Frerichs, K., and Spetzler, R. (2004). Natural history and general management of unruptured intracranial aneurysms. Neurosurg. Focus 17, E1.
Chicoine, M. R. (2003). Microsurgery and clipping: the gold standard for the treatment of intracranial aneurysms. J. Neurosurg. Anesthesiol. 15, 61-63.

Chyatte, D. (1996). "Diagnosis and management of aneurysmal subarachnoid hemorrhage," in The Practice of Neurosurgery, eds G. T. Tindall, P. R. Cooper, and D. L. Barrow (Baltimore: Williams and Wilkins), 1989-1995.

Chyatte, D., and Porterfield, R. (2001). Nuances of middle cerebral artery aneurysm microsurgery. Neurosurgery 48, 339-346.

Dashti, R., Hernesniemi, J., Niemela, M., Rinne, J., Lehecka, M., Shen, H., Lehto, H., Albayrak, B. S. Ronkainen, A., Koivisto, T., and Jaaskelainen, J. E. (2007). Microneurosurgical management of distal middle cerebral artery aneurysms. Surg. Neurol. 67, 553-563.

Dodel, R., Winter, Y., Ringel, F., Spottke, A., Gharevi, N., Muller, I., Klockgether, T., Schramm, J., Urbach, H., and Meyer, B. (2010). Cost of illness in subarachnoid hemorrhage: a german longitudinal study. Stroke 41 2918-2923.

Dott, N. M. (1933). Intracrainal aneurysms: cerebral arterioradiography: surgical treatment. Edinb. Med. J. 40, 219-234.

Ferns, S. P., Sprengers, M. E., van Rooij, W. J., Rinkel, G. J., van Rijn, J. C., Bipat, S., Sluzewski, M., and Majoie, C. B. (2009). Coiling of intracranial aneurysms: a systematic review on initial occlusion and reopening and retreatment rates. Stroke 40 , e523-e529.

Finlay, H. M., Whittaker, P., and Canham, P. B. (1998). Collagen organization in the branching region of human brain arteries. Stroke 29, 1595-1601.

Fiorella, D., Albuquerque, F. C., Deshmukh, V. R., and McDougall, C. G. (2005). Usefulness of the neuroform stent for the treatment of cerebral aneurysms: results at initial (3-6-mo) follow-up. Neurosurgery 56, 1191-1201; discussion 1201-1192.

Fiorella, D., Woo, H. H., Albuquerque, F. C., and Nelson, P. K. (2008). Definitive reconstruction of circumferential, fusiform intracranial aneurysms with the pipeline embolization device. Neurosurgery 62, 1115-1120; discussion 1120-1111.

Gonzalez, N., Murayama, Y., Nien, Y. L., Martin, N., Frazee, J., Duckwiler G., Jahan, R., Gobin, Y. P., and Vinuela, F. (2004). Treatment of unruptured aneurysms with gdcs: clinical experience with 247 aneurysms.
AJNR Am. J. Neuroradiol. 25, 577-583.

Guglielmi, G., Vinuela, F., Dion, J., and Duckwiler, G. (1991a). Electrothrombosis of saccular aneurysms via endovascular approach. Part 2: preliminary clinical experience. J. Neurosurg. 75 , 8-14.

Guglielmi, G., Vinuela, F., Sepetka, I., and Macellari, V. (1991b). Electrothrombosis of saccular aneurysms via endovascular approach. Part 1: electrochemical basis, technique, and experimental results. J. Neurosurg. 75, 1-7.

Higashida, R. T., Lahue, B. J., Torbey, M. T., Hopkins, L. N., Leip, E., and Hanley, D. F. (2007). Treatment of unruptured intracranial aneurysms: a nationwide assessment of effectiveness. AJNR Am. J. Neuroradiol. 28, 146-151.

Holmes, D. R. Jr., Savage, M., LaBlanche, J. M., Grip, L., Serruys, P. W., Fitzgerald, P., Fischman, D., Goldberg, S. Brinker, J. A., Zeiher, A. M., Shapiro, L. M., Willerson, J., Davis, B. R., Ferguson, J. J., Popma, J., King, S. B. III, Lincoff, A. M., Tcheng, J. E. Chan, R., Granett, J. R., and Poland, M. (2002). Results of prevention of restenosis with tranilast and its outcomes (presto) trial. Circulation 106, 1243-1250.

Iwamoto, H., Kiyohara, Y., Fujishima M., Kato, I., Nakayama, K., Sueishi, K., and Tsuneyoshi, M. (1999). Prevalence of intracranial saccular aneurysms in a japanese community based on a consecutive autopsy series during a 30-year observation period. The hisayama study. Stroke 30, 1390-1395.

Johnston, S. C. (2000). Effect of endovascular services and hospital volume on cerebral aneurysm treatment outcomes. Stroke 31, 111-117.

Johnston, S. C., Higashida, R. T., Barrow, D. L., Caplan, L. R., Dion, J. E., Hademenos, G., Hopkins, L. N., Molyneux, A., Rosenwasser, R. H., Vinuela, F., and Wilson, C. B. (2002). Recommendations for the endovascular treatment of intracranial aneurysms: a statement for healthcare professionals from the committee on cerebrovascular imaging of the american heart association council on cardiovascular radiology. Stroke 33, 2536-2544

Juvela, S., Porras, M., and Poussa, K. (2000). Natural history of unruptured intracranial aneurysms: probability of and risk factors for aneurysm rupture. J. Neurosurg. 93 379-387.

Juvela, S., Poussa, K., and Porras, M. (2001). Factors affecting formation and growth of intracranial aneurysms: a long-term followup study. Stroke 32, 485-491.

Kanaan, H., Jankowitz, B., Aleu, A., Kostov, D., Lin, R., Lee, K., Panipitiya, N., Gologorsky, Y., Sandhu, E., Rissman, L., Crago, E., Chang, Y. F., Kim, S. R., Jovin, T., and Horowitz, M. (2010). In-stent thrombosis and stenosis after neck-remodeling device-assisted coil embolization of intracranial aneurysms. Neurosurgery 67, 1523-1532; discussion 1532-1523.

Kondo, S., Hashimoto, N., Kikuchi, H., Hazama, F., Nagata, I., and Kataoka, H. (1997). Cerebral aneurysms arising at nonbranching sites. An experimental study. Stroke 28, 398-403; discussion 403-394.

Krex, D., Schackert, H. K., and Schackert, G. (2001). Genesis of cerebral aneurysms - an update. Acta Neurochir. (Wien) 143, 429-448; discussion 448-429.

Kulcsar, Z., Ernemann, U., Wetzel, S. G., Bock, A., Goericke, S., Panagiotopoulos, V., Forsting, M., Ruefenacht, D. A., and Wanke, I. (2010). High-profile flow diverter (silk) implantation in the basilar artery: efficacy in the treatment of aneurysms and the role of the perforators. Stroke 41, 1690-1696.

Kulcsar, Z., Houdart, E., Bonafe, A., Parker, G., Millar, J., Goddard, A. J., Renowden, S., Gal, G., Turowski, B., Mitchell, K., Gray, F. Rodriguez, M., van den Berg, R., Gruber, A., Desal, H., Wanke, I., and Rufenacht, D. A. (2011). Intraaneurysmal thrombosis as a possible cause of delayed aneurysm rupture after flow-diversion treatment. AJNR Am. J. Neuroradiol. 32, 20-25.

Lavine, S. D., Masri, L. S., Levy, M. L., and Giannotta, S. L. (1997). Temporary occlusion of the middle cerebral artery in intracranial aneurysm surgery: time limitation and advantage of brain protection. J. Neurosurg. 87, 817-824.

Lubicz, B., Bandeira, A., Bruneau, M., Dewindt, A., Baleriaux, D., and De Witte, O. (2009). Stenting is improving and stabilizing anatomical results of coiled intracranial aneurysms. Neuroradiology 51, 419-425.

Lubicz, B., Collignon, L., Raphaeli, G., Pruvo, J. P., Bruneau, M., De Witte, O., and Leclerc, X. (2010). Flow-diverter stent for the endovascular treatment of intracranial aneurysms: a prospective study in 29 patients with 34 aneurysms. Stroke 41, 2247-2253. 
Lubicz, B., Francois, O., Levivier, M., Brotchi, J., and Baleriaux, D. (2008). Preliminary experience with the enterprise stent for endovascular treatment of complex intracranial aneurysms: potential advantages and limiting characteristics. Neurosurgery 62, 1063-1069; discussion 1069-1070.

Luessenhop, A. J., and Velasquez, A. C. (1964). Observations on the tolerance of the intracranial arteries to catheterization. J. Neurosurg. 21, 85-91.

Lylyk, P., Miranda, C., Ceratto, R., Ferrario, A., Scrivano, E., Luna, H. R., Berez, A. L., Tran, Q., Nelson, P. K., and Fiorella, D. (2009). Curative endovascular reconstruction of cerebral aneurysms with the pipeline embolization device: the buenos aires experience. Neurosurgery 64, 632-642; discussion 642-633; quiz N636.

Masuda, H., Zhuang, Y. J., Singh, T. M., Kawamura, K., Murakami, M., Zarins, C. K., and Glagov, S. (1999). Adaptive remodeling of internal elastic lamina and endothelial lining during flow-induced arterial enlargement. Arterioscler. Thromb. Vasc. Biol. 19, 2298-2307.

Meng, H., Wang, Z., Hoi, Y., Gao, L., Metaxa, E., Swartz, D. D., and Kolega, J. (2007). Complex hemodynamics at the apex of an arterial bifurcation induces vascular remodeling resembling cerebral aneurysm initiation. Stroke 38, 1924-1931.

Menghini, V. V., Brown, R. D. Jr., Sicks, J. D., O'Fallon, W. M., and Wiebers, D. O. (1998). Incidence and prevalence of intracranial aneurysms and hemorrhage in olmsted county, minnesota, 1965 to 1995. Neurology 51, 405-411.

Mocco, J., Snyder, K. V., Albuquerque, F. C., Bendok, B. R., Alan, S. B., Carpenter, J. S., Fiorella, D. J., Hoh, B. L., Howington, J. U., Jankowitz, B. T., Liebman, K. M., Rai, A. T., Rodriguez-Mercado, R., Siddiqui, A. H., Veznedaroglu, E., Hopkins, L. N., and Levy, E. I. (2009). Treatment of intracranial aneurysms with the enterprise stent: a multicenter registry. J. Neurosurg. 110, 35-39.

Molyneux, A., Kerr, R., Stratton, I., Sandercock, P., Clarke, M., Shrimpton, J., and Holman, R. (2002). International subarachnoid aneurysm trial (isat) of neurosurgical clipping versus endovascular coiling in 2143 patients with ruptured intracranial aneurysms: a randomised trial. Lancet 360, 1267-1274.

Molyneux, A. J., Kerr, R. S., Birks, J., Ramzi, N., Yarnold, J., Sneade,
M., and Rischmiller, J. (2009). Risk of recurrent subarachnoid haemorrhage, death, or dependence and standardised mortality ratios after clipping or coiling of an intracranial aneurysm in the international subarachnoid aneurysm trial (isat): long-term follow-up. Lancet Neurol. 8, 427-433.

Murayama, Y., Nien, Y. L., Duckwiler, G., Gobin, Y. P., Jahan, R., Frazee, J., Martin, N., and Vinuela, F. (2003). Guglielmi detachable coil embolization of cerebral aneurysms: 11 years' experience. J. Neurosurg. 98, 959-966.

Ogilvy, C. S., Crowell, R. M., and Heros, R. C. (1995). Surgical management of middle cerebral artery aneurysms: experience with transsylvian and superior temporal gyrus approaches. Surg. Neurol. 43, 15-22; discussion 22-14.

Pereira, E. (2003). "History of endovascular aneurysm occlusion," in Management of Cerebral Aneurysms, eds P. D. LeRoux, H. R. Winn, and D. W. Newell (Philadelphia, PA: W. B. Saunders Company), 11-26.

Phillips, L. H. II, Whisnant, J. P., O'Fallon, W. M., and Sundt, T. M. Jr. (1980). The unchanging pattern of subarachnoid hemorrhage in a community. Neurology 30, 1034-1040.

Pierot, L., Spelle, L., and Vitry, F. (2008). Immediate clinical outcome of patients harboring unruptured intracranial aneurysms treated by endovascular approach: results of the atena study. Stroke 39, 2497-2504.

Pierot, L., Spelle, L., and Vitry, F. (2010). Immediate anatomic results after the endovascular treatment of unruptured intracranial aneurysms: analysis of the atena series. AJNR Am. J. Neuroradiol. 31, 140-144.

Piotin, M., Blanc, R., Spelle, L., Mounayer, C., Piantino, R., Schmidt, P. J., and Moret, J. (2010). Stentassisted coiling of intracranial aneurysms: clinical and angiographic results in 216 consecutive aneurysms. Stroke 41, 110-115.

Qureshi, A. I., Suri, M. F., Nasar, A., Kirmani, J. F., Divani, A. A., He, W., and Hopkins, L. N. (2005). Trends in hospitalization and mortality for subarachnoid hemorrhage and unruptured aneurysms in the united states. Neurosurgery 57, 1-8; discussion 1-8.

Raabe, A., Nakaji, P., Beck, J., Kim, L. J., Hsu, F. P., Kamerman, J. D., Seifert, V., and Spetzler, R. F. (2005). Prospective evaluation of surgical microscope-integrated intraoperative near-infrared indocyanine green videoangiography during aneurysm surgery. J. Neurosurg. 103, 982-989.

Raghavan, M. L., Ma, B., and Harbaugh, R. E. (2005). Quantified aneurysm shape and rupture risk. J. Neurosurg. 102, 355-362.

Raymond, J., and Roy, D. (1997). Safety and efficacy of endovascular treatment of acutely ruptured aneurysms. Neurosurgery 41, 1235 1245; discussion 1245-1236.

Rinkel, G. J., Djibuti, M., Algra, A., and van Gijn, J. (1998). Prevalence and risk of rupture of intracranial aneurysms: a systematic review. Stroke 29, 251-256.

Roberts, G. A., and Dacey, R. G. (2004). "General techniques of aneurysm surgery," in Management of Cerebral Aneurysms, eds P. D. LeRoux, H. R. Winn, and D. W. Newell (Philadelphia: Saunders), 563-583.

Rowe, A. J., Finlay, H. M., and Canham, P. B. (2003). Collagen biomechanics in cerebral arteries and bifurcations assessed by polarizing microscopy. $J$. Vasc. Res. 40, 406-415.

Ryu, C. W., Kwon, O. K., Koh, J. S., and Kim, E. J. (2010). Analysis of aneurysm rupture in relation to the geometric indices: aspect ratio, volume, and volumeto-neck ratio. Neuroradiology. doi: 10.1007/s00234-010-0804-4. [Epub ahead of print]

Serbinenko, F. A. (1974). Balloon catheterization and occlusion of major cerebral vessels. J. Neurosurg. 41, 125-145.

Shojima, M., Oshima, M., Takagi, K., Torii, R., Hayakawa, M., Katada, K., Morita, A., and Kirino, T. (2004). Magnitude and role of wall shear stress on cerebral aneurysm: computational fluid dynamic study of 20 middle cerebral artery aneurysms. Stroke 35, 2500-2505.

Singh, V., Gress, D. R., Higashida, R. T., Dowd, C. F., Halbach, V. V., and Johnston, S. C. (2002). The learning curve for coil embolization of unruptured intracranial aneurysms. AJNR Am. J. Neuroradiol. 23, 768-771.

Stapf, C., and Mohr, J. P. (2004). "Aneurysms and subarachnoid hemorrhage - epidemiology," in Management of Cerebral Aneurysms, eds P. D. LeRoux, H. R. Winn, and D. W. Newell (Philadelphia: Saunders), 183-187.

Stehbens, W. E. (1990). Pathology and pathogenesis of intracranial berry aneurysms. Neurol. Res. 12, 29-34.

Swietaszczyk, C., Maciaczyk, J., TafilKlawe, M., and Kasprzak, H. A. (2004). what is the origin of cerebral aneurysms? Prz. Lek. 61 115-119.

Szikora, I., Berentei, Z., Kulcsar, Z., Marosfoi, M., Vajda, Z. S., Lee, W., Berez, A., and Nelson, P. K. (2010). Treatment of intracranial aneurysms by functional reconstruction of the parent artery: the budapest experience with the pipeline embolization device. AJNR Am. J. Neuroradiol. 31, 1139-1147.

Takao, H., and Nojo, T. (2007). Treatment of unruptured intracranial aneurysms: decision and costeffectiveness analysis. Radiology 244, 755-766.

The International Study of Unruptured Intracranial Aneurysms Investigators (1998). Unruptured intracranial aneurysms - risk of rupture and risks of surgical intervention. International study of unruptured intracranial aneurysms investigators. N. Engl. J. Med. 339, 1725-1733.

Toth, M., Nadasy, G. L., Nyar, I., Kerenyi, T., and Monos, E. (2000). Are there systemic changes in the arterial biomechanics of intracranial aneurysm patients? Pflugers Arch. 439, 573-578.

van Gijn, J., Kerr, R. S., and Rinkel, G. J. (2007). Subarachnoid haemorrhage. Lancet 369, 306-318.

Vendrell, J. F., Costalat, V., Brunel, H., Riquelme, C., and Bonafe, A. (2011). Stent-assisted coiling of complex middle cerebral artery aneurysms: initial and midterm results. AJNR Am. J. Neuroradiol. 32, 259-263.

Wanke, I., Doerfler, A., Dietrich, U., Egelhof, T., Schoch, B., Stolke, D., and Forsting, M. (2002). Endovascular treatment of unruptured intracranial aneurysms. AJNR Am. J. Neuroradiol. 23, 756-761.

Weber, W., Bendszus, M., Kis, B., Boulanger, T., Solymosi, L., and Kuhne, D. (2007). A new selfexpanding nitinol stent (enterprise) for the treatment of wide-necked intracranial aneurysms: initial clinical and angiographic results in 31 aneurysms. Neuroradiology 49, 555-561.

Werner, S. C., Blakemore, A. H., and King, B. G. (1941). Aneurysm of the internal carotid artery within the skull; wiring and electrothermic coagulation. JAMA 116, 578-582.

Wiebers, D. O., Whisnant, J. P., Huston, J. III, Meissner, I., Brown, R. D. Jr., Piepgras, D. G., Forbes, G. S., Thielen, K., Nichols, D., O’Fallon, W. M., Peacock, J., Jaeger, L., Kassell, N. F., Kongable-Beckman, G. L., and Torner, J. C. (2003). Unruptured intracranial aneurysms: 
natural history, clinical outcome, and risks of surgical and endovascular treatment. Lancet 362, 103-110.

Winn, H. R., Jane, J. A. Sr., Taylor, J., Kaiser, D., and Britz, G. W. (2002). Prevalence of asymptomatic incidental aneurysms: review of 4568 arteriograms. J. Neurosurg. 96, 43-49.

Yong-Zhong, G., and van Alphen, H. A. (1990). Pathogenesis and histopathology of saccular aneurysms: review of the literature. Neurol. Res. 12, 249-255.

Yurt, A., Vardar, E., Selcuki, M., Erturk, A. R., Ozbek, G., and Atci, B. (2010). Biomarkers of connective tissue disease in patients with intracranial aneurysms. J. Clin. Neurosci. 17, 1119-1121.

Conflict of Interest Statement: The authors declare that the research was conducted in the absence of any commercial or financial relationships that could be construed as a potential conflict of interest.

Received: 08 April 2011; accepted: 29 June 2011; published online: 08 July 2011.

Citation: Seibert B, Tummala RP, Chow $R$, Faridar A, Mousavi SA and Divani $A A$ (2011) Intracranial aneurysms: review of current treatment options and outcomes. Front. Neur. 2:45. doi: 10.3389/fneur.2011.00045
This article was submitted to Frontiers in Endovascular and Interventional Neurology, a specialty of Frontiers in Neurology. Copyright (c) 2011 Seibert, Tummala, Chow, Faridar, Mousavi and Divani. This is an open-access article subject to a nonexclusive license between the authors and Frontiers Media SA, which permits use, distribution and reproduction in other forums, provided the original authors and source are credited and other Frontiers conditions are complied with. 